\title{
USO DE RUBAS (ULLUCUS TUBEROSUS) EN LA ELABORACIÓN Y CARACTERIZACIÓN DE YOGUR
}

\section{UTILIZATION OF RUBAS (ULLUCUS TUBEROSUS) AS AN ALTERNATIVE IN THE PREPARATION AND CHARACTERIZATION OF YOGURT}

\author{
Ricardo A. Parra ${ }^{1}$
}

Recibido para publicación: Enero 21 de 2015 - Aceptado para publicación: Abril 20 de 2015

\begin{abstract}
RESUMEN
El yogurt es una bebida láctea fermentada por bacterias ácido lácticas que tiene beneficios en la salud humana. El tubérculo rubas (Ullucus tuberosus) es una buena alternativa de nutrición humana; sin embargo, este producto es poco conocido y de poco consumo, por lo cual es necesario diversificar su consumo a través de la formulación de nuevos productos que lo incluyan como materia prima. Este trabajo consistió en elaborar un yogurt basado en concentrado de rubas, Se realizó un concentrado del tubérculo, que se añadió antes del periodo de fermentación y se comparó con un yogurt control que no contenía rubas. Durante cuatro semanas se monitoreo $\mathrm{pH}$, acidez y sinéresis. Además, se realizó análisis sensorial, microbiológico, y proximal. Los resultados indicaron que es viable su elaboración y estabilidad durante el almacenamiento. Los valores de $\mathrm{pH}$ y acidez tuvieron un comportamiento característico de un yogurt. Se presentó una disminución en los valores de sinéresis en el yogurt con concentrado de rubas. La evaluación sensorial indicó que el yogurt con concentrado de rubas tuvo buena aceptabilidad, además de estimular el crecimiento de bacterias ácido lácticas. Para el análisis proximal los dos tratamientos tuvieron valores similares. Se concluye que el concentrado de rubas en la elaboración de yogurt es una alternativa agroalimentaria viable.
\end{abstract}

Palabras Clave: Rubas, yogur, almacenamiento,caracterización, productos

\begin{abstract}
Yogurt is a food produced by bacterial fermentation of milk that is beneficial to human health. The tuber rubas (Ullucus tuberosus) is a good alternative to human nutrition; however, this food is underexploited and its consumption is limited to a small areas in South America. It is necessary to diversify its consumption through the development of new products based on this tuber. The objective of this work was to develop a yogurt based on rubas. A yogurt prepared based on a rubas concentrate was compared to a regular yogurt without rubas. $\mathrm{pH}$, acidity and syneresis were measured and sensorial, microbiological and proximal analysis were performed during four weeks. Acidifying bacterias were able to grow in rubas yogurt. Sensory evaluation

${ }^{1}$ Químico de Alimentos. Magister en Ciencia de los Alimentos. Docente.Universidad Pedagógica y Tecnológica de Colombia, Facultad de Ciencias Básicas, Escuela de Ciencias Químicas; email:ricardo.parra@uptc.edu.co; Dirección: Calle 45 No 4-79 Torre 6 Aptp 322. Tunja - Boyacá.
\end{abstract}


showed that the rubas yogurt had good acceptability. $\mathrm{pH}$, acidity, and the values of the proximal analysis were similar to the regular yogur. However, Syneresis values were lower in yogurt with rubas. Rubas tuber is a good alternative to prepare yogurt.

Keywords: Rubas, yogurt, storage

\section{INTRODUCCIÓN}

El yogurt es un producto lácteo fermentado por un cultivo iniciador compuesto de Streptococcus thermophilus y Lactobacillus delbrueckiisubsp. Bulgaricus especies termófilas, homofermentativas, presentes en una relación simbiótica, Ilamada protocooperación (Briceño et al. 2001; Zare et al. 2012); es el derivado lácteo de mayor consumo y mejor conocido, su proceso de fabricación tiene como objetivo principal desde el punto de vista fisicoquímico, provocar el descenso de $\mathrm{pH}$ de la leche hasta alcanzar las condiciones favorables para la coagulación (Pauletti et al. 2004; Parra 2013).

Como consecuencia de la acidificación del medio por bacterias acido lácticas (BAL), las proteínas de la leche se coagulan y precipitan, dando lugar a un producto con sabor, aroma y textura característicos (Blanco et al. 2006; Parra et al. 2011).

La primera y principal función de las BAL en el yogurt es la formación de ácidos orgánicos, principalmente ácido láctico (Rivas et al. 2007; Parra 2010) a una velocidad conveniente para asegurar una fermentación consistente y exitosa (Hill et al. 2002). El ácido láctico puede ser obtenido a través de la fermentación de la lactosa, que da un sabor ácido fresco en leches fermentadas, además de inhibir en parte la flora contaminante y patógena (Almanza 1991; Topisirovic et al. 2006).
Debido al aumento en la población mundial, es importante la prevención y tratamiento de enfermedades y maximizar la calidad de vida. Al respecto, se ha observado in vitro e in vivo que los productos lácteos fermentados con BAL tienen propiedades funcionales porque ayudan a incrementar la habilidad del cuerpo para resistir la invasión de patógenos y mantener bien la salud del huésped (Parra 2014). Las BAL han sido muy utilizados en aplicaciones terapéuticas que incluyen: prevención de enfermedades urogenitales (candidosis vaginal), protección y prevención contra la diarrea, control de enfermedades inflamatorias del intestino como enfermedad de Crohn y pouchitis, síndrome del intestino irritable (Ranadheera et al. 2010; Parra 2012), alivio de los síntomas de intolerancia a la lactosa, reducción del colesterol y reducción de la presión arterial. Otros beneficios incluyen la producción de enzimas, estabilización de la microflora, y reducción del riesgo de algunos cáncer, especialmente de colon (Lyer et al. 2010), prevención de alergias alimentarias (Kayanush et al. 2007), prevención, y tratamiento de ulcera gástrica causada por Helicobacter pylori (Baroutkoub et al. 2010).

El continente americano es uno de los centros donde se han originado y domesticado especies de plantas cultivadas como: papa, maíz, yuca, camote y frijol que han contribuido a la alimentación del mundo, pero también se han originado otras especies que son conocidas aún pero con potencial para ser explotadas 
tecnológicamente. Entre estas especies están los tubérculos denominados ullucus tuberosus, también Ilamados melloco, ulluco, papalisa, ruba, chugua, ulloco u olluma. Es una planta de la familia de las baselláceas, nativa del altiplano andino, donde se cultiva por su tubérculo y hojas comestibles (Cadima 2006), se han venido consumiendo durante más de 3000 años por millones de personas andinos como incas, quechuas y aymaras, como alimento básico. Estas variedades autóctonas se han adaptado a altitudes de entre 1800 y 3800 msnm, en un clima fresco y escasas precipitaciones (300 $\mathrm{mm}$ anuales) (Goldner et al. 2012).

Algunos estudios sobre el valor nutricional de los tubérculos andinos (como las rubas) confirman a estas como una alternativa para cubrir la creciente demanda en la alimentación humana, sin embargo, todavía hay poco conocimiento de la dinámica de crecimiento y las características potenciales de producción de dichos tubérculos. Es un hecho conocido que los tubérculos andinos desempeñan una multiplicidad de roles en las actividades humanas desde tiempos prehispánicos, sin embargo, en la actualidad, tubérculos como las rubas están casi olvidadas y subutilizadas (Condori et al. 2008).

Es por lo anterior que se propuso como objetivo en este trabajo evaluar el comportamiento de un yogur durante el almacenamiento en refrigeración elaborado a partir de concentrado de rubas, con el propósito de dar alternativas de uso agroalimentario a partir de productos autóctonos propios de la región andina colombiana.

\section{MATERIALES Y MÉTODOS}

\section{Localización del experimento}

La investigación tuvo lugar en los laboratorios de alimentos de la Universidad Pedagógica y Tecnológica de Colombia, sede Tunja, ubicada geográficamente a $5^{\circ} 32^{\prime} 07^{\prime \prime}$ latitud norte y $73^{\circ} 22^{\prime} 04^{\prime \prime}$ longitud oeste.

\section{Recolección y adecuación de las muestras Materiales}

Las materias primas utilizadas en la elaboración de yogurt fueron:

Rubas. Se recolectaron tubérculos propios de la zona de Boyacá, cultivados en fincas y comercializados en la plaza de mercado de la ciudad de Tunja. Se tomó una cantidad representativa del tubérculo teniendo precaución con la sanidad y calidad.

Leche. Se utilizó leche líquida entera ultrapasterizada de marca reconocida.

Leche en polvo. Se utilizó leche entera de marca reconocida obtenida en el mercado local.

Cultivo iniciador. El cultivo iniciador liofilizado conteniendo los microorganismos Lactobacillus delbrueckii subsp. Bulgaricus y Streptococcus thermophilus fueron adquiridos de una marca reconocida disponible en el mercado.

Azúcar. Se adquirió en el mercado local de marca reconocida.

\section{Elaboración del concentrado de rubas}

Para la elaboración se utilizó la metodología sugerida por Parra (2013) con las siguientes modificaciones, no se realizó infusión y no se llevó hasta $40^{\circ}$ Brix. 
Para la elaboración se utilizó 15\% p/p de rubas. Cada uno de los tubérculos se acondicionó empacándose en bolsas y mallas para su transporte hasta el laboratorio de análisis de alimentos a fin de conservar sus características. El lavado de las rubas se llevó a cabo por inmersión en agua potable y un agente germicida durante unos 5 minutos, luego se dejó secar a temperatura ambiente. Posteriormente se utilizó licuadora para reducir el tamaño a partículas, luego se extrajo el jugo evitando la presencia de partículas sólidas por medio de un filtrado con un cedazo ó lona fina. A continuación el jugo se concentró con sacarosa hasta 60 grados Brix a fuego medio en una estufa tipo industrial, este procedimiento se utilizó teniendo en cuenta la metodología sugerida por Parra (2012a) quien elaboró concentrado de rubas hasta 55 grados Brix.

\section{Preparación del cultivo iniciador}

Se precalentó $100 \mathrm{~mL}$ de leche ultrapasterizada a $41{ }^{\circ} \mathrm{C}$ y se añadió $1 \%$ de cultivo liofilizado que contenía una mezcla de bacterias formada por Streptococcus thermophilus y Lactobacillus bulgaricus. Posteriormente esta mezcla se incubó a $41{ }^{\circ} \mathrm{C}$ y fue utilizado como cultivo iniciador (Shori y Baba 2012).

\section{Elaboración de yogurt}

Para la elaboración del yogurt se tuvo en cuenta la metodología desarrollada por Zare et al. (2011), con algunas modificaciones como la concentración de leche en polvo y sacarosa utilizada. La leche entera ultrapasterizada se llevó a una temperatura de $43^{\circ} \mathrm{C}$, se añadió $3 \%$ leche en polvo, $5 \%$ de sacarosa y $1 \%$ de cultivo iniciador anteriormente preparado. La mezcla anteriormente preparada se homogenizó y se dividió en dos partes; a la primera se añadió
$15 \%$ de concentrado de rubas (cantidad necesaria para endulzar) y la segunda parte no tuvo modificaciones denominándo a este tratamiento yogurt control. Ambos tratamientos se incubaron a $43^{\circ} \mathrm{C}$ en varios recipientes de vidrio en una incubadora marca Binder hasta que las muestras alcanzaron un $\mathrm{pH}$ en un intervalo entre 4 y 4,5; valores recomendados por Olson y Aryana (2008) y Briceño et al. (2001), en sus estudios respectivos. Una vez alcanzado el pH mencionado anteriormente, las muestras de yogurt se empacaron en recipientes de plástico con tapa y con volumen de $250 \mathrm{~mL}$ para cada análisis, se almacenó en condiciones de refrigeración a $4^{\circ} \mathrm{C}$ durante un periodo de 4 semanas; los días 2, 9, 18 y 30 de almacenamiento en refrigeración se determinaron $\mathrm{pH}$, acidez titulable y sinéresis. Además se realizó análisis sensorial, análisis proximal y recuento microbiológico de bacterias ácido lácticas.

\section{Métodos \\ Caracterización fisicoquímica}

pH. El pH del yogurt fue medido con un pHmetro (marca Hanna), durante los días 1,6, 12, 20 y 30 se determinó valor de $\mathrm{pH}$ (945.27/90 de la AOAC).

Acidez titulable. La acidez titulable fue medida por titulación de $10 \mathrm{~mL}$ de muestra con $0,1 \mathrm{ml} / \mathrm{L} \mathrm{NaOH}$ utilizando fenolftaleína como indicador.El resultado se expresó como porcentaje de ácido láctico (962.12/90 de la $\mathrm{AOAC})$. Esta determinación se realizó los días $1,6,12,20$ y 30 en condiciones de refrigeración $4^{\circ} \mathrm{C}$.

Sinéresis. Se pesaron $20 \mathrm{~mL}$ de cada una de las muestras de yogur y se sometieron a centrifugación por un tiempo de 20 minutos a una velocidad de $4000 \mathrm{rpm}$. Luego de 
la centrifugación se obtuvo los $\mathrm{mL}$ del sobrenadante (lactosuero) y se calculó el grado de sinéresis mediante la relación entre el volumen del sobrenadante y el volumen de la muestra (Charoenrein et al. 2008).La sinéresis fue determinada los días 2, 9, 18 y 30 de almacenamiento.

Evaluación sensorial. Se realizó una prueba de aceptación, utilizando escala hedónica de cinco puntos. A cada uno de los calificativos empleados en la escala, se le asignó un valor de 1 a 5, siendo 5 la mejor calificación. Para la evaluación de yogurt con concentrado de rubas, se utilizaron 30 jueces consumidores potenciales del producto tal y como lo propuso Mendoza et al. (2007) y Parra (2013) en sus trabajos de investigación.

Escala utilizada para la evaluación sensorial:

$$
\begin{aligned}
& \text { 1: me disgusta muchísimo } \\
& \text { 2: me disgusta moderadamente } \\
& \text { 3: no me gusta ni me disgusta } \\
& \text { 4: me gusta moderadamente } \\
& \text { 5: me gusta muchísimo }
\end{aligned}
$$

\section{Conteo de células viables ácido lácticas en yogurt} Agua peptonada

Veinte gramos de agua peptonada fueron mezclados con 1 litro de agua destilada, la mezcla fue distribuida en tubos seguido por autoclave a $121^{\circ} \mathrm{C}$ por 20 minutos.

\section{Preparación de la muestra}

Las muestras de yogurt (1 mL) fue individualmente mezclado con $9 \mathrm{~mL}$ de agua peptonada. La mezcla fue agitada y una serie de diluciones fueron preparadas al utilizar agua peptonada.

\section{Enumeración de bacterias acido lácticas utilizando el método vertido en placa}

Las bacterias acido lácticas fueron enumeradas como son descritas por Kailasapathy et al. (2008), con algunas modificaciones. El agar MRS fue preparado al mezclarlo con agua (62 $\mathrm{gL}^{-1}$ de agua destilada), Las cajas de Petri fueron selladas con parafina y se dejaron a temperatura ambiente para permitir que el agar se solidificara. Posteriormente, las placas se invirtieron y se colocaron en la incubadora a $37^{\circ} \mathrm{C}$ por 48 horas.

\section{Caracterización proximal}

Se seleccionó una muestra de yogurt control y una muestra de yogurt con concentrado de rubas para realizar los siguientes análisis cada uno por duplicado:

Determinación de humedad. Se llevó a cabo por el método gravimétrico 930.15/90 de la AOAC (1990).

Determinación de cenizas. Se realizó siguiendo el método 942.05/90 de la AOAC(1990), secando previamente las muestras a $110{ }^{\circ} \mathrm{C}$ y posteriormente calcinadas a una temperatura de $550{ }^{\circ} \mathrm{C}$, hasta peso constante.

Proteína. Se efectúo mediante el método de Kjeldalh de acuerdo a la técnica 955.04/90 (AOAC 1990), el cual determinó la concentración de nitrógeno presente en la muestra, para luego ser transformado a través de un factor en proteína de 6,38.

Fibra cruda. Se tomaron muestras previamente desengrasadas y se les realizó digestión ácida en presencia de $\mathrm{H}_{2} \mathrm{SO}_{4}$ 0,255 $\mathrm{N}$ y digestión alcalina en presencia de $\mathrm{NaOH} 0,313$ N. Para la determinación del porcentaje de fibra cruda, fue utilizado el método Weende 962.09/90 de la AOAC (1990). 
Determinación de extracto etéreo. El ensayo se realizó utilizando el método 920.39/90 de la AOAC de 1990.

Carbohidratos. Se determinó por diferencia.

\section{Análisis estadístico}

Para el análisis de la información los datos se exportaron al programa Microsoft Office Excel ${ }^{\circledR}$ para realizar las tablas presentadas. Cada medición en los tratamientos se realizó por duplicado; se realizó un ANOVA con una confiabilidad del 95\%. Los análisis de $\mathrm{pH}$, acidez, sinéresis y análisis proximal se realizaron por duplicado.

\section{RESULTADOS Y DISCUSIÓN}

\section{pH y acidez}

El $\mathrm{pH}$ de yogurt con concentrado de rubas y control se observa en la figura 1, en los dos casos, el pH disminuyó durante el almacenamiento, observándo una disminución en los tratamientos. Al inicio del experimento los valores para el yogur que contenía rubas y yogur control fueron 4,39 y 4,47 respectivamente y al finalizar, los valores fueron para el yogur con rubas $y$ yogur control 4,22 y 4,42 respectivamente, el análisis de varianza indica que el efecto de la adición de rubas en el yogur si fue significativo $(\mathrm{P}>0.05)$ en el $\mathrm{pH}$.

La disminución en los valores de $\mathrm{pH}$ tal y como muestra la figura 1 puede atribuirse a que durante el almacenamiento en condiciones de refrigeración, ocurrió una actividad microbiana por parte de las bacterias ácido lácticas presentes en el yogurt tal y como lo señalan Lubbers et al. (2004) para yogurts almacenados durante más de 20 días bajo refrigeración. En otros estudios realizados por Sahan et al. (2008); Ruiz y Ramírez (2009) y Olson y Aryana (2008), reportaron que el $\mathrm{pH}$ de yogurt disminuía durante el almacenamiento en condiciones de refrigeración entre 3,8 y 4,5. Hassan y Amjad (2010), mencionan que la reducción de $\mathrm{pH}$ en el yogurt puede ser debido a la degradación de la lactosa en ácido láctico, esta disminución de pH durante el almacenamiento se ve reflejada en la velocidad de acidificación.

De acuerdo a las investigaciones de Kailasapathy et al. (2008), los cambios bajos de $\mathrm{pH}$ son debido además a cambios en el contenido de ácido en el yogurt, en este caso ácido láctico; de otro lado, los valores de $\mathrm{pH}$ del yogurt que contenía concentrado de rubas siempre fueron menores a los del yogurt control, observándo que al final del experimento el $\mathrm{pH}$ del yogurt que contenía concentrado de rubas y el yogurt control fue 4,2 y 4,4 respectivamente.

La figura 1 muestra además el efecto de almacenamiento en la acidez de yogurt control y yogurt con concentrado de rubas. La adición de rubas incrementó el nivel de acidificación, en comparación con el control. Al inicio del experimento los valores de acidez para el yogur que contenía rubas y yogur control fueron 0,79 y 0,63\% de ácido láctico respectivamente y al finalizar en el día 30, los valores fueron para el yogur con rubas y yogur control 1,32 y $0,9 \%$ de ácido láctico respectivamente. El análisis estadístico indica que si hubo efecto significativo $(\mathrm{P}<0.05)$ en los dos tratamientos en la 


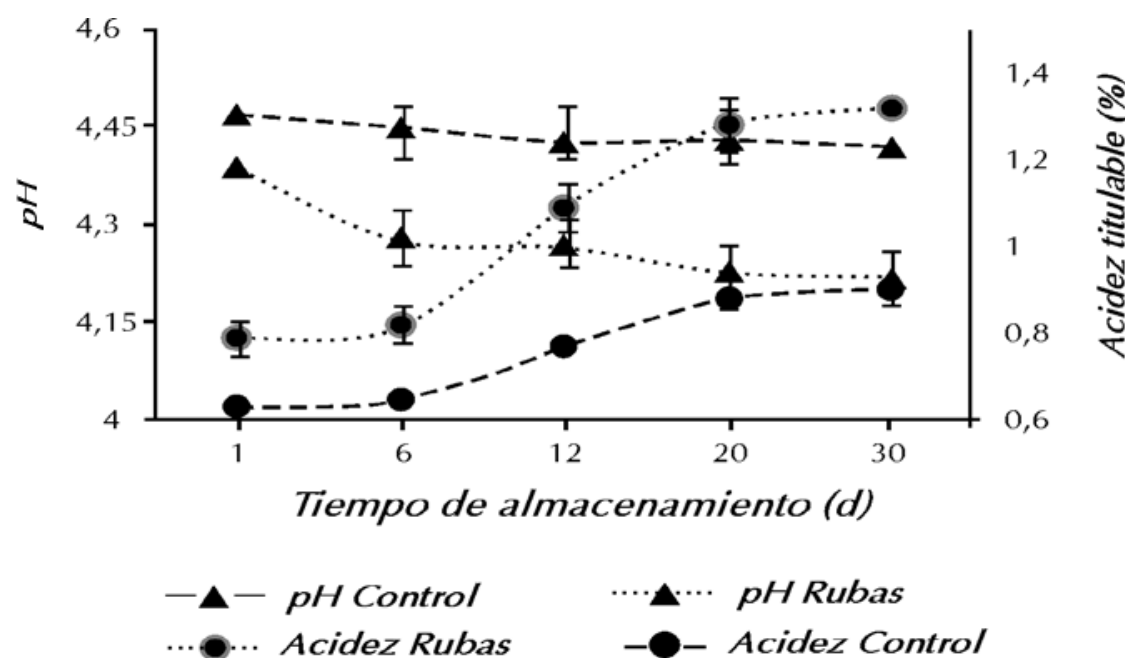

Figura 1. Acidez titulable y $\mathrm{pH}$ de yogurt control y yogurt con concentrado de rubas durante los días $1,6,12,20$ y 30 de almacenamiento en refrigeración.

adición de rubas al yogur afectando así la acidez. Lo anterior puede atribuirse a una hidrólisis de los diferentes componentes del concentrado de rubas, como también, a los posibles cambios bioquímicos presentes en el yogurt durante el almacenamiento. Al respecto Briceño et al. (2001), menciona que durante el almacenamiento de un yogurt, la acidez aumenta en condiciones de refrigeración máximo hasta 1,5\% expresada en ácido láctico. Igualmente, Hussain et al. (2009), encontraron en un yogurt natural al final del experimento en el día 10 de almacenamiento una acidez como máximo de 1,44\% expresado en ácido láctico.

\section{Sinéresis}

En la tabla 1 se describe el comportamiento de la sinéresis para los dos tratamientos; es notable que el yogurt que contenía concentrado de rubas tuvo un efecto en la reducción de la sinéresis durante el almacenamiento; la diferencia de la sinéresis en las dos muestras es muy amplia al final del almacenamiento, 4,5 y $51 \%$ para el yogurt con concentrado de rubas y yogurt control respectivamente. El análisis estadístico indica que no hubo efecto significativo $(P<0.05)$ en los dos tratamientos.

El grado de sinéresis para el yogurt control aumentó durante el almacenamiento debido a la pérdida de estabilidad y retención de agua de los componentes de yogurt; caso contrario ocurrió con la otra muestra que contenía concentrado de rubas donde la baja sinéresis presentada se debió posiblemente a que el contenido de fibra ayudó a evitarla (Díaz et al. 2004).

Al respecto Díaz et al. (2004), reportó valores para sinéresis entre 45-65\% para un yogurt control (sin fibra, elaborado con leche entera y sacarosa).

Este comportamiento puede ser explicado además por la disminución en el pH durante 
TEMAS AGRARIOS - Vol. 20:(1) Enero - Junio 2015 (91 - 102)

Tabla 1. Grado de sinéresis durante el almacenamiento de yogurt control y yogurt con concentrado de rubas

\begin{tabular}{ccc}
\hline Día & Yogurt control (\%) & Yogurt con concentrado de rubas $(\%)$ \\
\hline 2 & 0 & $5,55 \pm 0,52$ \\
9 & $22 \pm 0,73$ & $5,55 \pm 0,48$ \\
18 & $30 \pm 0,52$ & $5,66 \pm 0,62$ \\
30 & $51 \pm 0,49$ & $4,51 \pm 0,35$ \\
\hline
\end{tabular}

Tabla 2. Conteo viable de bacterias ácido lácticas en yogurt control y yogurt con concentrado de rubas durante 30 días de almacenamiento a $4^{\circ} \mathrm{C}$.

\begin{tabular}{ccc}
\hline $\begin{array}{c}\text { Tiempo } \\
\text { Almacenamiento }\end{array}$ & $\begin{array}{c}\text { Yogurt control } \\
(\text { UFC/g) }\end{array}$ & $\begin{array}{c}\text { Yogurt con concentrado de rubas } \\
(\mathbf{U F C} / \mathbf{g})\end{array}$ \\
\hline Día 5 & $2,21 \times 10^{5}$ & $2,35 \times 10^{5}$ \\
Día 30 & $4,7 \times 10^{5}$ & $1,16 \times 10^{6}$ \\
& & \\
\hline
\end{tabular}

el almacenamiento, lo cual puede tener efecto de contracción en la matriz de la micela de caseína causando más eliminación de lactosuero (Achanta et al. 2007). Peng et al. (2009), mencionan que el contenido de sólidos en un yogurt ayudan a prevenir la separación de lactosuero, igualmente mencionan que un aumento en el contenido de proteína podría resultar en una textura fuerte con menos separación de lactosuero.

Al respecto Isanga y Zhang (2009), reportaron que altos contenidos de proteína en yogurt está asociado con valores bajos de sinéresis.

\section{Análisis microbiológico}

En la tabla 2 se observa que el concentrado de rubas estimuló el crecimiento de las bacterias ácido lácticas en el yogurt durante el almacenamiento. Lo anterior se debe probablemente a que el concentrado de rubas aportó a las BAL de yogurt una fuente de energía para estimular su crecimiento. El valor final de recuento para bacterias ácido lácticas para el yogurt con extracto de rubas es similar al presentado por Shori y Baba (2012), reportando para un yogurt comercial elaborado con leche de vaca un valor de 1,4×106 ufc/g al día 21 del almacenamiento. Este valor es similar al obtenido mostrado en la tabla 2 en el yogurt con concentrado de rubas $1,16 \times 106 \mathrm{ufc} / \mathrm{mL}$.

\section{Evaluación sensorial}

Los resultados de la evaluación sensorial para el yogurt con concentrado de rubas se detallan en la tabla 3. Se observa que atributos como sabor, color, olor y cuerpo / textura tuvieron una aceptación favorable.

Dentro de los parámetros evaluados tuvo mayor aceptabilidad el color, que es característico de las rubas, seguido del sabor; es de resaltar que el concentrado de rubas adicionadas al 
Tabla 3. Propiedades sensoriales de yogurt con concentrado de rubas

\begin{tabular}{ccc}
\hline $\begin{array}{c}\text { Parametro } \\
\text { evaluado }\end{array}$ & $\begin{array}{c}\text { Me gusta } \\
\text { mucho }(\%)\end{array}$ & $\begin{array}{c}\text { Me gusta } \\
\text { moderadamente (\%) }\end{array}$ \\
\hline Color & $87 \quad \pm 1,68$ & $13 \quad \pm 1,54$ \\
Olor & $80 \quad \pm 1,53$ & $20 \quad \pm 1,61$ \\
Sabor & $86,7 \pm 1,82$ & $13,3 \pm 1,66$ \\
Cuerpo/textura & $80 \quad \pm 1,73$ & $20 \quad \pm 1,85$ \\
Aceptación global & $100 \pm 1,02$ & - \\
\hline
\end{tabular}

Tabla 4. Análisis proximal de yogurt control y yogurt con concentrado de rubas

\begin{tabular}{ccc}
\hline $\begin{array}{c}\text { Parametro } \\
\text { evaluado }\end{array}$ & $\begin{array}{c}\text { Me gusta } \\
\text { mucho (\%) }\end{array}$ & $\begin{array}{c}\text { Me gusta } \\
\text { moderadamente (\%) }\end{array}$ \\
\hline Proteina (\%) & $2,84 \pm 0,22$ & $3,20 \pm 0,12$ \\
Grasa (\%) & $4,11 \pm 0,66$ & $2,84 \pm 0,47$ \\
Fibra cruda (\%) & $0,25 \pm 0,02$ & $0,34 \pm 0,16$ \\
Carbohidratos (\%) & 12,28 & 14,78 \\
Cenizas (\%) & $0,69 \pm 0,01$ & $0,64 \pm 0,02$ \\
Humedad (\%) & $79,83 \pm 0,002$ & $78,20 \pm 0,02$ \\
Calorias (Cal/g) & 81,87 & 87,66 \\
\hline
\end{tabular}

yogurt no le confirió sabores desagradables o cualquier característica indeseable al yogurt según la evaluación sensorial.

\section{Análisis proximal}

Se observa en la tabla 4 que el yogur que contenía rubas tuvo un ligero incremento en el contenido de proteína, fibra y carbohidratos respecto al yogur control, sin embargo el análisis de varianza indicó que el efecto de la adición de rubas en el yogur no fueron significativos $(\mathrm{P}>0.05)$ para los valores proximales.
Estas pequeñas diferencias pueden ser explicadas por que las rubas proporcionaron estos componentes y aportaron proteína, fibra, carbohidratos y calorías por la forma de preparación del concentrado. Según la Norma Técnica Colombiana 805, el contenido de grasa para un yogur elaborado con leche entera debe ser mínimo de $2,5 \%$ e igualmente para proteína el valor mínimo debe ser 2,5\%, ambos tratamientos coinciden con las recomendaciones de la NTC mencionada. 


\section{CONCLUSIONES}

Los resultados de este estudio demostraron que la adición de concentrado de rubas en el yogurt estimuló el crecimiento y viabilidad de bacterias ácido lácticas, por consiguiente el pH disminuyó y la acidez aumentó como consecuencia del efecto estimulador de las rubas sobre el metabolismo de estas bacterias. El yogurt con $15 \%$ de concentrado de rubas mostró disminuir valores en sinéresis y aumentar el valor nutritivo, además de tener una buena aceptabilidad sensorial.

Los valores de acidez, recuento de bacterias ácido lácticas, proteína y materia grasa estuvieron dentro de los valores recomendados por la Norma Técnica Colombiana 805.

El yogurt obtenido con adición de rubas es una buena alternativa de uso en la alimentación humana, debido a su gran valor nutricional.

\section{REFERENCIAS}

Achanta, K., Aryana, K., Boeneke, C. 2007. Fat free plain set yogurts fortified with various minerals. LWT 40:424-429.

Almanza, F., y Barrera, E. 1991. Tecnología de leche y derivados, Bogotá, Editorial Unisur, Bogotá 255-310.

\section{A.O.A.C. (Association of Official Analytical} Chemists). 1990. Official Methods of Analysis. Virginia

Baroutkoub, A., Zamir, R., Beglarian, R., Hassan, J., Zahra, S., Seyed, M.,Mohammad, E. 2010. Effects of probiotic yoghurt consumption on the serum cholesterol levels in hypercholestromic cases in Shiraz, Southern Iran.Scientific Research and Essays 5: 2983-2986.

Blanco, S., Pacheco, E., Fragenas, N. 2006. Evaluación física y nutricional de un yogurt con frutas tropicales bajo en calorías. Revista Facultad Agronomía 32:131-144.

Briceño, A., Martínez, R., García, K. 2001. Viabilidad y actividad de la flora láctica (streptococcus salivarius ssp thermophilus y lactobacillus delbrueckii ssp bulgaricus) del yogurt en Venezuela.Acta Científica Venezolana 52:46-54.

Cadima, X. 2006. Botánica Económica de los Andes Centrales .Editores: M. Moraes R., B. Ollgaard, L. P. Kvist, F. Borchsenius \& H. Balslev. Universidad Mayor de San Andrés, La Paz: 347-369.

Condori, B., Mamani, P., Botello, R., Patiño, F., Devaux, A.,Ledent, F. 2008. Agro physiological characterization and parameterization of Andean tubers: Potato (Solanumsp.), oca (Oxalis tuberosa), isaño (Tropaeolum tuberosum) and papalisa (Ullucus tuberosus). European Journal Agronomy 28:526-540.

Charoenrein, S., Tatirat, O.,Muadklay, J. 2008. Use of centrifugation-filtration for determination of syneresis in freeze-thaw starch gels. Carbohydrate Polymers 73:143-147.

Díaz, B., Sosa, M., Vélez, J. 2004. Efecto de la adición de fibra y disminución de grasa en las propiedades fisicoquímicas del yogurt. Revista Mexicana de Ingeniería Química 3:287-305. 
Goldner, M., Pérez, O., Pilosof, M., Armada, M. 2012. Comparative study of sensory and instrumental characteristics of texture and color of boiled under-exploited Andean tubers. LWT - Food Science and Technology 47: 83-90.

Hassan, A., Amjad I. 2010. Nutritional evaluation of yoghurt prepared by different starter cultures and their physiochemical analysis during storage. African Journal of Biotechnology 9:2913-2917.

Hill, C., Okeeffe, T., Ross, P. 2002. Antimicrobial factors produced by lactic acid bacteria. Encyclopedia of Food Sciences and nutrition 14:273-285.

Hussain, I., Rahman, A., Atkinson N. 2009. Quality comparison of probiotic and natural yogurt. Pakistan Journal of Nutrition 8: 9-12.

Isanga, J. y Zhang, G. 2009. Production and evaluation of some physicochemical parameters of peanut milk yoghurt. LWT - Food Science and Technology 42: 11321138.

Kailasapathy, K., Harmstorf, I., Phillips, M. 2008. Survival of Lactobacillus acidophilus and Bifidobacterium animalis ssp. lactis in stirred fruit yogurts. Food Science and Technology 41:1317-1322.

Kayanush, J., Aryanaa, B.,McGrew, P. 2007. Quality attributes of yogurt with Lactobacillus casei and various prebiotics. LWT 40: 18081814.
Lyer, R., Tomar, S., Kapila, S., Mani, J., Singh, R. 2010. Probiotic properties of folate producing Streptococcus thermophilus strains Food Research International 43:103-110.

Lubbers, S., Decourcelle, N., Vallet, N., Guichard, E. 2004. Flavor release and rheology behaviour of strawberry fat free stirred yogurt during storage. Journal Agricultural Food Chemistry 52:3077-3082.

Mendoza, R., Trujillo, Y., Duran, D. 2007. Evaluación del almidón de ñame espino (dioscórea rotundata) como estabilizante en la elaboración de yogur entero tipo batido. Revista Bistua 5:97-105.

Olson, D.,Aryana, J. 2008. An excessively high Lactobacillus acidophilus inoculation level in yogurt lowers product quality during storage LWT 41:911-918.

Parra, R. 2014. Encapsulación de sábila (Aloe vera) y su efecto durante la incubación de yogur. Revista cultura científica 12:66-73.

Parra, R. 2013. Efecto del té verde (camellia sinensis I.) en las características fisicoquímicas, microbiológicas, proximales y sensoriales de yogurt durante el almacenamiento en refrigeración. Revista @limentch Ciencia y Tecnología Alimentaria 11:56-64.

Parra, R. 2012. Yogur en la salud humana. Revista Lasallista de Investigación 9:162-177.

Parra, R. 2012a. Evaluación fisicoquímica, proximal y sensorial de una bebida láctea fermentada con concentrado de rubas (ullucus tuberosus). Memorias I de congreso 
Internacional en Investigación e Innovación en Ciencia y Tecnología de Alimentos. Bogotá, Junio de 2012, 225-227.

Parra, R., Martínez, C., Espinosa, J. 2011. Comportamiento fisicoquímico de stevia, fructosa, dextrosa y lactosa como endulzantes a diferentes concentraciones durante el tiempo de incubación en la elaboración de yogurt entero. Bistúa: Revista de la Facultad de Ciencias Básicas 9:15-20.

Parra, R. 2010. Review. Bacterias acido lácticas: papel funcional en los alimentos. Revista Biotecnología en el sector agroalimentario y agroindustrial 8:93-105.

Pauletti, M., Santa Cruz, L., Mazza, G., Rozycki, S., Sabbag, N., Costa S. 2004. Fabricación de yogurt con células inmovilizadas. Revista Ciencia y Tecnología Alimentaria. Sociedad Mexicana de Nutrición y Tecnología de Alimentos 4:190-196.

Peng, Y., Serra, M., Home, D., Lucey, J. 2009. Effect of fortification with various types of milk protein on the rheological properties and permeability of nonfat set yogurt. Journal of Food Science 74:666-673.

Ranadheera, R., Baines, S., Adams, C. 2010. Review Importance of food in probiotic efficacy. Food Research International 43:1-7.

Rivas, C., Chacón, Z., Otoniel, J., Guerrero, B., López, G. 2007. Aislamiento, identificación y caracterización de bacterias ácido lácticas de un queso venezolano ahumado andino artesanal. Su uso como cultivo iniciador. Revista Científica FCV-Luz 3:301-308.
Ruiz, J. y Ramírez, M. 2009. Elaboración de yogurt con probióticos (Bifidobacterium spp. y Lactobacillus acidophillus) e inulina. Revista Facultad Agronomía (LUZ) 26:223-242.

Sahan, N., Yasarb, K.,Hayaloglu, A. 2008. Physical, chemical and flavour quality of non-fat yogurt as affected by a B-glucan hydrocolloidal composite during storage. Food Hydrocolloids 22:1291-1297.

Shori, A., Baba, A. 2012. Viability of lactic acid bacteria and sensory evaluation in Cinnamomum verum and Allium sativumbio-yogurts made from camel and cow milk. Journal of the Association of Arab Universities for Basic and Applied Sciences 11:50-55.

Topisirovic, L., Kojic, M., Fira, D., Golic, N., Strahinic, I., Lozo, J. 2006. Potential of lactic acid bacteria isolated from specific natural niches in food production and preservation. International Journal of Food Microbiology 48:318-326.

Zare,F., Boye, J.,Orsat, V. 2011. Microbial, physical and sensory properties of yogurt supplemented with lentil flour. Food Research International 44:2482-2488.

Zare, F., Champagne, C., Simpson, B., Orsat, V.,Boye, J. 2012. Effect of the addition of pulse ingredients to milk on acid production by probiotic and yoghurt starter cultures. Food Science and Technology 45:155-160. 